\title{
Geriatrics for juniors: tomorrow's geriatricians or another lost tribe?
}

\author{
${ }^{1} \mathrm{JM}$ Fisher, ${ }^{2} \mathrm{~K}$ Hunt, ${ }^{3} \mathrm{MJ}$ Garside \\ ${ }^{1}$ St5, Geriatric and General Internal Medicine, Northumbria Healthcare NHS Foundation Trust, Ashington; ${ }^{2}$ Consultant in Geriatric and \\ General Internal Medicine, Newcastle upon Tyne Hospitals NHS Foundation Trust; ${ }^{3}$ St6, Geriatric and General Internal Medicine, Newcastle \\ upon Tyne Hospitals NHS Foundation Trust, Newcastle upon Tyne, UK
}

\section{ABSTRACT}

Background: To meet the needs of the ageing population, more geriatric medicine doctors are required. We aimed to determine: (i) career preferences of junior doctors with an interest in geriatric medicine, (ii) factors influencing the likelihood of junior doctors undertaking a career in geriatric medicine and (iii) whether a geriatric medicine conference for junior doctors influenced their views on the specialty and their likelihood of choosing it as a career option.

Methods: All delegates who registered to attend the 'Geriatrics for Juniors' conference (G4J) were invited to complete both a pre- and post-conference survey online. Delegates' free-text responses were subjected to thematic analysis. Differences between paired ordinal data from pre- and post-conference surveys were determined using the Wilcoxon signed rank test.

Results: A total of 108 delegates attended G4J. Pre- and post-conference survey response rates were $67 \%$ and $51 \%$ respectively. Commonly reported deterrents to a career in geriatric medicine included 'being the medical registrar' $(27.1 \%$ of respondents) and 'second-class specialty' $(20.6 \%)$. There was a statistically significant difference between pre- and post-conference responses, with a tendency towards less agreement with the statement 'the prospect of being the medical registrar puts me off applying for higher specialty training in geriatric medicine' $(Z=-2.512$; $\mathrm{p}=0.012$ ).

Conclusions: The perceived unattractive nature of the medical registrar role may deter some junior doctors from a career in geriatric medicine. A lack of clarity regarding the nature of the specialty still exists. Targeted educational interventions, such as G4J, may positively influence junior doctors' perceptions of the specialty and the role of the medical registrar.

KEYWORDS geriatric medicine, medical registrar, workforce planning

\author{
Correspondence to JM Fisher \\ Northumbria Healthcare NHS \\ Foundation Trust \\ Wansbeck General Hospital \\ Woodhorn Lane \\ Ashington NE63 9JJ, UK
}

e-mail james@aeme.org.uk

DECLARATION OF INTERESTS No conflict of interest declared.

\section{INTRODUCTION}

The population of the UK is ageing, with the proportion of people over 65 years of age projected to rise from $17 \%$ in 2010 to $23 \%$ in 2035.' In 2011, the Royal College of Physicians (RCP) suggested that in order to meet the needs of the elderly population, a ratio of one consultant geriatrician per 50,000 population was required; ${ }^{2}$ however, in many regions of the UK this was not being achieved. While there has been an expansion in the numbers of both consultant and trainee geriatricians, recent work has shown that increasing numbers of training posts are unfilled, ${ }^{3}$ raising concerns that the future UK health service may not be adequately staffed to cope with the ageing population. The importance of ensuring that doctors are better equipped to care for an ageing population has been highlighted in a number of recent high-profile policy documents, including the Shape of Training Report ${ }^{4}$ and the Francis Report. ${ }^{5}$

A number of factors have previously been identified that may be adversely affecting recruitment to specialty training in geriatric medicine. First, serial survey work has demonstrated that while there has been an increase in the number of UK medical schools teaching and assessing geriatric medicine, a comparatively small amount of time is allocated to teaching on ageing. ${ }^{6.7}$ Second, evidence exists suggesting that some students have negative attitudes towards older people $^{8}$ and perceive the specialty to lack prestige. ${ }^{9}$ Recent work by $\mathrm{Ni}$ Chroinin et al..$^{10}$ examined the career preferences of a cohort of medical students in the final 18 months of their degree. While $31 \%$ of respondents suggested that they were open to considering a career in geriatric medicine, only $1 \%$ of respondents named geriatric medicine as their preferred specialty. Third, a recent RCP report on the role of the medical registrar cited the nature of this post as a potential deterrent to applicants undertaking a career in general internal medicine." The work-life balance as a medical registrar was also repeatedly cited as a deterring feature in a survey of foundation year two doctors. ${ }^{12}$ Serial surveys of graduates demonstrated that medical hospital specialties have declined in popularity between 2002 and 2008. ${ }^{13}$ 
We aimed to determine: (i) career preferences of junior doctors who have expressed an interest in geriatric medicine, (ii) factors influencing the likelihood of junior doctors undertaking a career in geriatric medicine and (iii) whether a geriatric medicine conference, designed specifically for junior doctors, influenced their views on the specialty and their likelihood of choosing it as a career option.

\section{METHODS}

The Association for Elderly Medicine Education, a nonprofit organisation set up by three geriatric medicine trainees in the north east of England, held its inaugural conference, 'Geriatrics for Juniors' (G4J) in September 20I3. The aims of G4J were to attract junior doctors to the specialty of geriatric medicine and to provide practical advice that junior doctors could apply to the care of elderly patients.

Advertised nationally via deanery mailing lists and social media, the conference included lectures on the majority of geriatric medicine sub-specialties, predominantly delivered by geriatric medicine consultants. The programme also included sessions that focused on the practicalities of a career in the specialty: applying to a training programme (delivered by the regional training programme director for geriatric medicine) and worklife balance (delivered by the regional head of school of medicine). Slides from all of the presentations at G4J are available at http://aeme.org.uk/g4j-20I3-slides. To directly address the role of the medical registrar, a question and answer session was organised that allowed delegates to ask a panel of three current registrars about their experiences in the role of the medical registrar.

All delegates who registered to attend G4J received an email link to a pre-conference survey, which was completed online. The content of this survey is available at https://www.surveymonkey.com/s/g4j. After the conference, a second survey was sent to all delegates, again via email. The link for the survey was sent one week after the conference and was available online for a sixweek period. The content of this survey is available at https://www.surveymonkey.com/s/g4j_postconference.

Ethical approval for this research was sought. Newcastle and North Tyneside Research Ethics Committee stated that this project did not require review by an NHS Research Ethics Committee.

\section{Survey content}

In the pre- and post-conference surveys delegates were asked to indicate, using a ten-point Likert scale ( I=extremely unlikely; I0=extremely likely), how likely it was that they would apply for higher specialty training in geriatric medicine. In both the pre- and post-conference surveys delegates were also asked to indicate, using a five-point Likert scale, their level of agreement with the following statements:

- The prospect of being the medical registrar puts me off applying for higher specialty training in geriatric medicine.

- A geriatric medicine consultant has a wide variety of career options open to him/her.

Delegates were also asked to provide free-text comments to the following questions:

- If you were to decide against a career in geriatric medicine, what career option/specialty would you most likely apply for?

- What do you think puts people off doing geriatric medicine as a specialty?

In the post-conference survey, delegates were asked to indicate, using a five-point Likert scale, their level of agreement with the following statements:

- Since attending the conference I have applied knowledge acquired at G4J to my clinical practice.

- Since attending G4J, I feel more confident that I am able to provide safe and effective care to elderly patients.

Delegates were also asked whether their views on geriatric medicine had changed since the conference. If their views had changed, delegates were prompted to expand on this via free-text comments.

\section{Analysis}

Differences between paired ordinal data derived from pre- and post-conference surveys were determined using the Wilcoxon signed-rank test. The Mann-Whitney $U$-test was used to assess for differences between groups' responses to questions producing ordinal data.A $P$ value of $<0.05$ was considered significant. Significance values are reported to 3 decimal places. For qualitative analysis, thematic analysis (by JMF) was used to generate codes that described the content of the free-text data arising from the surveys. A second researcher (MJG) with experience in qualitative research, also performed this process. This researcher was provided with the transcript of participants' comments but was blinded with regards to the first coding framework produced. Subsequently the researchers met to compare analyses and reach a consensus on the most appropriate themes and codes to describe the data captured.

\section{RESULTS}

\section{Response rate}

Altogether, 180 people registered to attend G4J, of whom 108 actually attended on the day. Sixty-two per cent (I07//80) completed the pre-conference survey, 72 of whom subsequently attended G4J. A total of 55 out of the 107 delegates who attended the conference 
TABLE I Factors that deter people from doing geriatric medicine: thematic analysis

\begin{tabular}{|l|c|}
\hline Theme & \% of respondents \\
\hline Being the Med Reg/GIM on calls & 27.1 \\
\hline Social issues & 22.4 \\
\hline $\begin{array}{l}\text { Second-class specialty (too general/ } \\
\text { lack of prestige/'not a real specialty') }\end{array}$ & 20.6 \\
\hline Therapeutic nilhism & 19.6 \\
\hline Dealing with cognitively impaired patients & 11.2 \\
\hline Workload/work-life balance & 11.2 \\
\hline Complexity & 10.3 \\
\hline Lack of procedures & 7.5 \\
\hline Lack of intellectual stimulation & 4.7 \\
\hline $\begin{array}{l}\text { Lack of positive training experiences } \\
\text { in geriatrics }\end{array}$ & 3.7 \\
\hline Lack of opportunity for private practice & 1.9 \\
\hline Lack of research opportunities & 0.9 \\
\hline Lack of evidence-based medicine & 0.9 \\
\hline
\end{tabular}

completed the post-conference survey. The pre- and post-conference survey response rates for attending delegates were $67 \%$ and $51 \%$ respectively. In total, 45 people attended the conference and completed both pre- and post-conference surveys.

\section{Delegate demographics}

Of the 108 delegates, 84 (77.8\%) were female. The majority of delegates were either foundation doctors (48.6\%) or core medical trainees (36.7\%). The remaining delegates included medical students $(0.9 \%)$, nurses $(\mathrm{I} .8 \%)$ and specialty trainees (I.8\%).

\section{Pre-conference results}

What specialty would you do instead of geriatrics?

The three most commonly selected alternative career paths were general practice, acute medicine and palliative care (chosen by $23 \%, 16.8 \%$ and $12 \%$ of respondents respectively).

What factors put people off doing geriatric medicine as a specialty?

Themes arising from a thematic analysis of delegates' free-text responses are displayed in Table I. The three most commonly arising themes were "being the medical registrar/general internal medical (GIM) on calls' (27.1\%), 'social issues' (22.4\%) and 'second-class specialty' (20.6\%).

\section{Comparison of responses pre- and post-conference}

'The prospect of being the medical registrar puts me off applying for higher specialty training in geriatric medicine' Comparison of responses to the pre-conference survey between those attending and those not attending the conference revealed no significant difference between the groups $(p=0.069)$. Pre-post analysis of responses to this question was restricted to those delegates who

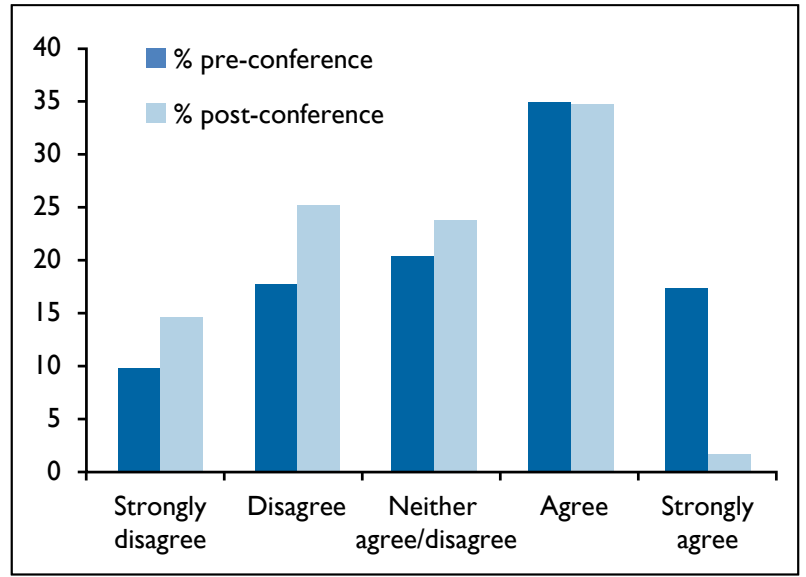

FIGURE I Responses to 'The prospect of being the medical registrar puts me off applying for geriatric medicine'.

attended the conference and provided paired survey responses. Before the conference, $52.2 \%$ of respondents agreed that the prospect of being the medical registrar put them off applying for higher specialty training in geriatric medicine; $27.5 \%$ disagreed.After the conference, $36.4 \%$ of respondents agreed with the statement and $39.8 \%$ disagreed (Figure I). There was a statistically significant difference between responses pre- and postconference $(Z=-2.5 \mid 2 ; p=0.012)$, with a tendency towards less agreement with the statement.

In terms of gender, men appeared to be less likely than women to indicate that being the medical registrar put them off applying to geriatric medicine (mean pre response $=2.56$ vs. 3.55 ), but the small numbers of males who completed both pre- and post-conference surveys precluded any meaningful statistical analysis.

'A geriatric medicine consultant has a wide variety of career options open to him/her'

Pre-post analysis of responses to this question was restricted to those delegates who attended the conference. Before the conference, $82.6 \%$ agreed that geriatrics provided a varied career choice; $5.8 \%$ disagreed.After G4J, 92.6\% agreed with this statement, with no person disagreeing. Analysis of paired data revealed a statistically significant difference in survey responses, with a shift towards greater agreement with this statement in the post-conference survey $(Z=-2.854 ; p=0.004)$.

'How likely are you to undertake higher specialty training in geriatric medicine?"

For this question pre-post analysis of responses was restricted to those delegates who attended the conference. In the pre-conference survey, the mean response to this question was $7.32(\mathrm{SD}=2.2)$. Postconference, the mean response to this question was $7.56(\mathrm{SD}=2.2)$. There was no significant difference between scores in pre- and post-conference surveys $(Z=-1.392 ; p=0.164)$. There was no statistically significant 
difference in the likelihood of undertaking a career in geriatrics between males and females.

\section{Post-conference feedback \\ 'Did your views on geriatric medicine change post G4J?' Of the 55 respondents, 33 to the post-conference survey felt that their views on geriatric medicine had changed following the conference; free-text responses were provided by 28 of these respondents. Thematic analysis of free-text feedback provided by respondents revealed four main themes: 15 respondents reported that since the conference they had a greater appreciation of the variety of sub-specialties in geriatric medicine. Nine respondents reported that they now considered the specialty to be a more viable career option. Three respondents noted they were now more interested in the specialty. One respondent wrote that she had gained an appreciation that geriatric medicine is a specialty in its own right.}

\section{General feedback}

With regards to the conference, $77 \%$ of survey respondents agreed that they had applied knowledge acquired at G4J to their clinical practice, with only $6.6 \%$ disagreeing. A total of $98.4 \%$ agreed that they would be interested in attending future geriatric medicine educational events, while $73.8 \%$ agreed that since the conference they felt more confident in their ability to provide safe and effective care to elderly patients, with only $1.6 \%$ disagreeing.

\section{DISCUSSION}

Our data provide a unique insight into the career preferences of a cohort of UK junior doctors who have expressed an interest in geriatric medicine, along with their perceptions of the specialty. It supports the suggestion that many junior doctors with an interest in geriatric medicine are deterred from exploring a career in the specialty due to concerns regarding the prospect of being the medical registrar. This work demonstrates that a targeted intervention to address junior doctors' concerns regarding the medical registrar role can positively influence their opinions. Conclusions regarding the duration of this effect cannot be made and it is therefore uncertain whether this will ultimately translate into delegates applying for geriatric medicine training posts.

The fact that $20 \%$ of delegates who completed the preconference survey intimated that geriatric medicine was a 'second-class' specialty or that a geriatrician was not a specialist is concerning. Recent survey data has suggested a gap in the general public's knowledge of what a geriatrician does, ${ }^{14}$ but seeing such beliefs in a cohort of doctors who have expressed an interest in the specialty is surprising. Similarly, the relatively high occurrence of themes of frustration with social issues, therapeutic nihilism and unwillingness to deal with cognitive impairment is concerning. These themes may in part be explained by the limited time allocated to specific teaching on geriatric medicine in UK medical schools. ${ }^{7}$ As Gordon et al. ${ }^{7}$ stressed, simply being 'around' old people does not guarantee learning and understanding of core geriatric topics such as frailty, cognitive impairment or comprehensive geriatric assessment.

More than a quarter of survey respondents cited being the medical registrar and GIM on calls as a deterrent to a career in geriatric medicine. Ten per cent of survey respondents reported that perceived high workload and poor work-life balance put them off. These findings are consistent with a recent survey of foundation year two doctors, where the work-life balance of a medical registrar was cited by many as a deterrent to exploring a career in specialties that include general hospital medicine." Similarly, a 2006 survey of UK geriatric medicine trainees found that 28 (10.1\%) had regrets about becoming a geriatrician; more than half of them cited general internal/acute medicine as the reason for their regret. ${ }^{14}$

It is interesting to note that the most common reasons reported in our survey that deter people from doing geriatric medicine do not appear in the most common deterrents reported by undergraduates in the work by $\mathrm{Ni}$ Chroinin et al. ${ }^{10}$ It is likely that medical students have a relative lack of insight into the realities and practical aspects of hospital-based clinical medicine, in particular the role of the medical registrar and that these perceptions develop once they start working as junior doctors. The negative perceptions associated with the role of the medical registrar, and their detrimental effect on recruitment, were acknowledged in the Shape of Training Report ${ }^{4}$ and by the RCP." To ensure that an adequately staffed medical workforce is maintained, it is vitally important that these perceptions are addressed.

Regarding 'what factors put people off doing geriatric medicine as a specialty', we acknowledge that the phrasing of this question is such that some responses may reflect what respondents feel might be off-putting to trainees in general, as opposed to themselves. We believe that the answers provided are still enlightening as they are likely to reflect genuine 'grass roots' views on the specialty held by junior doctors. The generalisability of this work is limited by the fact that our survey population was a self-selecting group of junior doctors who had paid to attend an event about geriatric medicine. This cohort can therefore be expected to have a higher than average level of enthusiasm or interest in the specialty. Furthermore, the slightly lower response rate to the post-conference survey compared with the pre-conference survey has the potential to bias results towards those with more interest, since this group is perhaps more likely to respond to such a survey. 
We acknowledge that many of the delegates who attended G4J worked in the north of England, thus introducing the possibility of local bias. We do, however, believe that a sufficient geographical spread of delegates was achieved (as can be seen from the map of where delegates originated $\left.{ }^{16}\right)$ to make our conclusions applicable to a wider UK audience.

Our data also highlight that many delegates with an interest in geriatric medicine may be 'lost' to other specialties, particularly general practice. Future research might explore the career pathways of junior doctors who have expressed an interest in geriatric medicine, particularly those who then opt for alternative career pathways.

\section{REFERENCES}

I Office for National Statistics. Population ageing in the United Kingdom, its constituent countries and the European Union. London: Office for National Statistics; 2012.

2 Royal College of Physicians. Consultant physicians working with patients: the duties, responsibilities and practice of physicians in medicine. 5th ed. London: RCP; $201 \mathrm{I}$.

3 Fisher JM, Garside M, Hunt $\mathrm{K}$ et al. Geriatric medicine workforce planning: a giant geriatric problem or has the tide has turned? Clin Med20 |4; |4:102-6.http://dx.doi.org/I0.786I/clinmedicine. |4-2-I02

4 Greenaway D. Shape of training review: securing the future of excellent patient care. London: Shape of Training; 20I3. Available from: http:// www.shapeoftraining.co.uk/static/documents/content/Shape_of_ training FINAL Report.pdf 53977887.pdf

5 Mid Staffordshire NHS Foundation Trust Inquiry. Independent inquiry into care provided by Mid Staffordshire NHS Foundation Trust, January 2005 - March 2009. London: Stationery Office; 2010.

6 Gordon AL, Blundell AG, Gladmann JR et al. Are we teaching our students what they need to know about ageing? Results from the National Survey of Undergraduate Teaching in Ageing and Geriatric Medicine. Age Ageing 2010; 29:385-8. http://dx.doi.org/ I0.1093/ageing/afq0 I I

7 Gordon AL, Blundell AG, Dhesi JK et al. UK medical teaching about ageing is improving but there is still work to be done: the Second National Survey of Undergraduate Teaching in Ageing and Geriatric Medicine. Age Ageing 2014; 43:293-7. http://dx.doi. org/l0.1093/ageing/aft207

8 Reuben DB, Fullerton JT, Tschann JM et al. Attitudes of beginning medical students toward older persons: a five-campus study. The University of California Academic Geriatric Resource Program Student Survey Research Group. J Am Geriatr Soc 1995; 43:1430-6.

\section{CONCLUSION}

With the UK's ageing population there is a great need to ensure the future workforce is adequately staffed to meet the population's needs. There are growing concerns regarding recruitment to hospital-based medical specialties in part due to the perceived unattractive nature of the medical registrar role; some junior doctors with an interest in geriatric medicine are deterred from exploring a career in the specialty because of these perceptions. A lack of clarity regarding the nature of the specialty of geriatric medicine still exists, even among doctors who have an interest in it. Targeted educational interventions such as 'Geriatrics for Juniors' may positively influence junior doctors' perceptions of both the specialty and the role of the medical registrar.

9 Robbins TD, Crocker-Buque T, Forrester-Paton C et al. Geriatrics is rewarding but lacks earning potential and prestige: responses from the national medical student survey of attitudes to and perceptions of geriatric medicine. Age Ageing 20II; 40:405-8. http://dx.doi.org/10.1093/ageing/afr034

I0 Ní Chróinín D, Cronin E, Cullen W et al. Would you be a geriatrician? Student career preferences and attitudes to a career in geriatric medicine. Age Ageing 2013; 42:654-7. http://dx.doi. org/l 0.1093/ageing/aft093

II Royal College of Physicians. The medical registrar: empowering the unsung heroes of patient care. London: RCP; 2013.

12 Chaudhuri E, Mason NC, Newbery N et al. Careers: factors affecting recruitment to general medicine in the UK. Clin Med 2013; 13:330-5.

I3 Goldacre MJ, Goldacre R, Lambert TW. Doctors who considered but did not pursue specific clinical specialties as careers: questionnaire surveys.J R Soc Med 2012; 105: 166-76. http://dx.doi. org/10.1258/jrsm.2012.II0173

14 Campbell JY, Durso SC, Brandt LE et al. The unknown profession: a geriatrician. J Am Geriatr Soc 2013; 61:44-9. http://dx.doi. org/I0.1 III/jgs. I2II5

I5 Briggs S, Atkins R, Playfer J et al. Why do doctors choose a career in geriatric medicine? Clin Med 2006; 6:469-72.

16 British Geriatrics Society. Geriatrics for juniors. London: BGS; 2013. Available from: http://britishgeriatricssociety.wordpress. com/2013/10/16/geriatrics-for-juniors 